\title{
A NOTÍCIA E A CARNE PODRE Efeitos temporais do jornalismo
}

\author{
Letícia Matheus $^{1}$
}

\begin{abstract}
Resumo: $O$ artigo trata do tema do jornalismo, como modo específico de interação social com valores e expectativas próprios em espaços sociais determinados. Neste caso, a observação recai sobre a mediação do tempo cotidiano realizada por três dos mais longevos periódicos do Rio de Janeiro: Jornal do Commercio (1827), O Fluminense (1878) e o Jornal do Brasil (1891-2010). Apresenta uma tipologia dos usos do tempo pelo jornalismo, a importância da periodicidade e do efeito de novidade para a manutenção de seu consumo e status comunicacional. Reflete também sobre a tensão entre perenidade e efemeridade da notícia. Procura definir jornalismo por um viés temporal.
\end{abstract}

Palavras-chave: Jornalismo. Mediações. Temporalidade.

\begin{abstract}
This article deals with the theme of journalism, as a certain way of social interaction with its own values and expectations in certain social spaces. In this case, the observation is on the mediation of everyday life performed by three of the most longlasting newspapers from Rio de Janeiro: Jornal do Commercio (1827), O Fluminense (1878) and Jornal do Brasil (1891-2010). It presents a typology of the uses of time by journalism, the importance of periodicity and the effect of novelty for the maintenance of its consumption and communicational status. It also reflects on the tension between permanence and ephemerality of the news. It seeks to define journalism through a temporal bias.
\end{abstract}

Key-words: Journalism. Mediations. Temporality.

O que faz com que um texto seja percebido como jornalístico? O que parece óbvio é hoje preocupação pertinente, já que a importância dessa forma de comunicação acabou popularizando o conhecimento de suas práticas, incluindo linguagem e procedimentos. Assim, formas de representação assemelhadas ao jornalismo foram sendo apropriadas de muitas maneiras, em diferentes instâncias das sociedades. Esse movimento foi incrementado em grande medida pelas novas tecnologias digitais, que agilizaram e baratearam o custo de ser lido e visto. E, mais recentemente, até a legislação tem favorecido o embaralhamento de fronteiras entre o jornalístico e o não-jornalístico.

\footnotetext{
1 Doutora em Comunicação pela UFF e professora da Universidade Plínio Leite, Niterói. Email:
} leticia_matheus@yahoo.com.br. 
Entretanto, nem os jornais impressos, forma material mais tradicional do jornalismo, foram homogêneos, transitando entre o libelo político, o registro público, a crônica, o folhetim, o entretenimento, a notícia, a ficção etc. Assim, restaram ao jornalismo muito mais definições de condições de existência do que conceitos propriamente ditos.

Rizzini (1946) definiu como condição necessária para o jornalismo a regularidade das transmissões e a garantia de liberdade de imprensa. Morel (2005) usa como critério a existência de uma esfera pública. Barbosa (2008) chama a atenção para a necessidade de abstração do pensamento, de modo que seja possível a mercantilizarão de um bem imaterial. Definições quanto à forma (linguagem) são obrigadas a se limitar a período e lugar precisos, pois, quando se amplia o recorte temporal e espacial, a definição não se sustenta, já que o jornalismo transita por muitas linguagens.

Em relação ao conteúdo, o problema não é menor, pois os produtos jornalísticos são diversos. Costuma-se dizer que se trata da transmissão de informações públicas relevantes, mas é difícil definir informação, muito menos pública e relevante. Até porque boa parte das histórias contadas nos jornais é privada; e relevante é algo bastante subjetivo. E informação é algo tão vago e tão presente em todos os momentos da vida que é difícil identificá-la, muito menos atribuí-la ao jornalismo. Uma cor, um suspiro, um traço são informação.

Este artigo procura definir jornalismo a partir da perspectiva temporal. Ainda assim, a esperança de encontrar uma regularidade nas relações com o tempo que atravessa o fazer jornalístico ao longo dos últimos 200 anos no Rio de Janeiro é quase nenhuma.

De qualquer forma, falhando a vertente temporal, opta-se por uma definição simples: jornalismo é a experiência comunicativa considerada jornalismo. Embora pareça fraudulenta, essa definição permite incorporar desde já a dimensão cultural intrínseca ao jornalismo, o que deve ser levado em conta em qualquer análise comunicacional desse objeto. Portanto, neste trabalho, procura-se pelo menos uma característica própria ao jornalismo, de caráter temporal, que faz com que as pessoas o reconheçam como jornalismo; não outra coisa. Para isso, optou por problematizá-lo a partir de sua historicização. O que se destaca aqui não é o veículo “jornal” mas a relação social "jornalismo".

Tomando como parâmetro a definição de Rizzini (1946), existe uma relação temporal que condiciona a percepção do jornalismo: a condição de periodicidade. Que implicações traz essa relação temporal para o reconhecimento e o valor do jornalismo?

Não se pretende responder a essa pergunta integralmente, apenas trazendo um esboço de reflexão, mas a principal hipótese é que a periodicidade gera expectativa de novas leituras, garantindo, por sua vez, a necessidade do jornalismo. Seria esse poder de narratividade 
cotidiana que marcaria o valor do jornalismo como sistema relevante de representação, a ponto de se perpetuar por tantos anos, ainda que de diferentes formas, e se valendo de diversas estratégias de legitimação.

Se isso é verdade, a relação temporal mediada por essa forma de comunicação favoreceria uma consciência histórica bastante particular, característica da Modernidade e de grupos sociais inseridos de determinadas maneiras no mundo social. Toda uma ideia de progresso, de evolução e de superação performática do passado estaria favorecida por meio de uma articulação narrativa do tempo que achata as multiplicidades temporais, bem como as contradições inerentes ao processo histórico.

Portanto, toma-se a notícia como ponto central para historicizar o jornalismo e as relações temporais que as pessoas estabelecem por meio dele. Frequentemente, tanto no senso comum quanto no meio acadêmico, associam-se os conceitos de jornalismo e notícia, que não coincidem integralmente. Por isso, a notícia será tratada aqui como um problema de ordem temporal, tanto na sua historicidade quanto nas concepções de tempo embutidas nela.

\section{Efeito notícia}

Ao observar jornais antigos, tem-se a sensação que as categorias cognitivas do presente não são muito eficientes para decifrar aquelas páginas. Não somente devido a outros vocabulários e formas de expressão, mas principalmente porque os parâmetros que orientam sua leitura contemporaneamente talvez não existissem. Assim, o primeiro impacto foi interpretar que notícias, historiografia e textos políticos ainda não tinham sofrido diferenciação, não tanto do ponto de vista editorial-gráfico e redacional, mas, sobretudo, do ponto de vista de seu status comunicativo.

Esses rótulos, evidentemente, não estavam explícitos, nem hoje estão, sendo muito mais projeções teóricas acadêmicas do que algo imanente aos textos. Entretanto, o material político sobreviveu com o nome de "opinião" e precisou ser separado da notícia. Esta, por sua vez, foi elevada a uma categoria privilegiada no jornalismo, tornando-se sua metonímia. Tanto é assim que hoje, no senso comum, noticiário e jornalismo são categorias quase indiferenciadas. Mas onde foi parar a história?

Certamente, misturou-se em parte com a "opinião", na medida em que se trata de um momento de reflexão explícita da realidade. Mas as interpretações de uma época considerada socialmente ida (o passado), tão comuns aos periódicos do século XIX, parecem ter desaparecido, salvo ocasiões excepcionais, tais como em edições especiais. 
É verdade que a palavra "história" continua em moda. Embora exista algo que somente a chancela do que é "histórico" lhe confere, o jornalismo é considerado uma narrativa do presente. (FRANCISCATO, 2005) Daí se realizou uma distinção grosseira entre notícia (narrativa do presente) e historiografia (narrativa do passado, ainda que elaborada por um jornal). Assim, foi-se à procura de um momento de diferenciação entre notícia e historiografia midiática em três dos mais longevos periódicos do Rio de Janeiro: Jornal do Commercio (1827), O Fluminense (1891) e o Jornal do Brasil (1891-2010), este último cancelado na sua versão impressa em agosto de 2010.

A busca foi se tornando cada vez mais labiríntica, pois se verificaram, desde 1808, tanto uma preocupação com retrospectivas e sínteses explicativas aparentadas aquilo que se entende por historiografia quanto um forte senso de novidade, que se atribui hoje à notícia.

O problema foi que se partia de um anacronismo, do qual, a rigor, não se escapa. Estava-se criando uma identidade noticiosa com o tempo imediato, inédito, que poderia não ser característica do conceito oitocentista de notícia.

Um dos erros mais frequentes ao se lançar a um trabalho de historicização é projetar expectativas e significados do presente no passado (JASMIM e FERES, 2006). Segundo Koselleck (apud idem, ibidem), existem quatro situações que precisam ser consideradas: a) quando o fenômeno e seu conceito se mantém estáveis; b) quando mudam harmonicamente; c) quando o fenômeno permanece estável no tempo mas seu conceito muda; e d) o fenômeno muda mas o conceito permanece o mesmo.

A consagração da notícia, da forma como se concebe hoje, remete mais acentuadamente à década de 1950. De fato, o conceito não possuía, no século XIX, o mesmo significado de hoje. Segundo o dicionário Moraes e Silva (1813), notícia era sinônimo de conhecimento, informação no sentido de erudição. Portanto, nada indica que houvesse necessidade de estar associada a novidades.

Ainda assim, manteve-se a hipótese da vinculação do sentido de atualidade embutido na notícia, já que a forma como ela era articulada na época talvez possa enganar a nós, leitores habituados aos leads e subleads atuais.

A manutenção da hipótese inicial, com alguns novos cuidados, deu-se porque o interesse era perceber não tanto o significado exclusivamente linguístico da notícia (tanto sua formulação estética quanto semântica) mas sua dimensão temporal. Segundo Koselleck (apud MOTZKIN, 2006), os conceitos possuem uma história não somente por suas variações semânticas, mas, também, devido a sua variabilidade temporal. Eles carregam camadas 
temporais de significados anteriores. Além disso, os conceitos, sobretudo referentes ao pensamento político, remetem a uma extensão temporal e a uma intensidade da experiência.

Assim, os sentidos que os conceitos adquirem num determinado contexto cultural dependem da profundidade temporal a que se referem (tanto em direção ao passado quanto em direção ao futuro) e do grau de intensidade da experiência a eles associado. Essa teoria é fundamental para pensar a experiência jornalística e sua relação com a tão propalada aceleração na Modernidade.

Portanto, notícia e história estavam misturadas, inclusive porque as fronteiras dos saberes, no século XIX, não estavam cristalizadas. Sequer "história" possuía o caráter atual de processo social. Tratava-se simplesmente da "narração de sucessos civis, militares ou políticos”. (MORAES E SILVA, 1813)

Por exemplo, o mesmo texto que noticiava as comemorações na cidade pelo aniversário de 20 anos de dom Pedro I trazia também uma longa interpretação acerca de várias possibilidades para os rumos do país a partir do nascimento do herdeiro de Pedro I e analisava também o papel do imperador e de dom João na história recente. Tratava-se de uma mescla de análise política, história e notícia.

Num caso como esse, é importante perceber que, numa época em que a notícia, tal como elaborada hoje, não era modelo narrativo para o jornalismo (pelo menos não prioritário, como sua marca narrativa identitária), um esforço de "historicização" não pode ser compreendido como algo divorciado da prática cotidiana num jornal. Buscar uma separação entre notícia e um "contar a história" seria cometer o anacronismo de atribuir ao jornalismo do século XIX expectativas e modos de leitura dos séculos XX e XXI.

O desafio ao se pretender estudar como se dava a percepção de notícia no século XIX no Rio, e como era a leitura da novidade, é recuperar "o leitor em atividade", como diz Darnton (1995). Segundo o historiador, "a leitura não é simplesmente uma habilidade, e sim uma maneira de fazer sentido" (ibem, ibidem: 159, grifo nosso), ou seja, comunicação.

A principal estratégia metodológica proposta por Darnton e desenvolvida nesta pesquisa foi analisar o leitor implicado no texto, com o auxílio da teoria narrativa de Ricoeur (1994), inspirada na análise de três romances ("Mrs. Dalloway", de Virginia Woolf, "A Montanha Mágica", de Thomas Mann, e "Em busca do tempo perdido", de Marcel Proust) que ele apresenta em seu "Tempo e Narrativa, tomo II" (1994). Observamos não tanto os tempos verbais, mas as articulações de tempo organizadas em amostras de textos desses jornais. A partir daí, pudemos interpretar o sentido do tempo que estava sendo proposto ao leitor, e que tipo de consciência temporal era necessária para que o leitor compreendesse, 
interagisse com o jornal e produzisse sentido sobre aqueles textos. Por isso, o jornal pôde ser aqui compreendido como um mediador das relações temporais do leitor com seu mundo.

Para entender como o público do Jornal do Commercio o lia no século retrasado, é preciso um esforço de deslocamento em direção a nós mesmos enquanto "outros". (RICOEUR, 1991) Esse deslocamento, entretanto, é sempre inviável em última instância, pelo menos enquanto se pretender reconstituir o passado como se deu. Mas um esforço de interpretação é sempre possível, de modo a tentar relativizar as supostas certezas de hoje.

Desde seu primeiro ano de existência (1827), o Jornal do Commercio publicou balanços comerciais, resumo das variações cambiais, atividades portuárias, oscilações de preço dos principais gêneros comercializados na época, entre outras informações. Nos primeiros anos, esses balanços se limitavam às atividades do último mês. Aos poucos, o cálculo se ampliou para as médias anuais, divulgadas ou em dezembro ou em janeiro do ano seguinte. Essas informações eram fundamentais para que os comerciantes planejassem suas atividades, ou seja, elas possuíam um caráter instrumental explícito. Entretanto, essas revisões econômicas viriam a ser acompanhadas de análises pretensamente historiográficas na década de 1830. (MATHEUS, 2010)

Enquanto a última página era ocupada por quadros com todas as médias dos preços que vigoraram no ano anterior, a primeira página trazia uma "análise de fundo": "Avoa fugitivo o anno de 1835", dizia a edição de 02/01/1836. O jornal descreve a situação política nas "principais nações", explorando as consequencias dos movimentos liberais de 1830.

Todos os anos foram apresentados como muito especiais, como forma de justificar a "presentividade" do jornal, e, em vários momentos, o diário explica como entende o seu papel frente aos acontecimentos e à história, como neste exemplo, de $1^{\circ}$ e 2 de janeiro de 1840 :

\section{ANNO DE 1839}

Não passará de certo desapercebido nos annaes da humanidade o anno que ainda hontem terminou, e cujos principais acontecimentos devemos aqui esboçar. Não he tenção nossa usurpar o buril da história, nem, engolfandonos em sublimes, philosophicas considerações, proclamar o já sediço apophthegma - o presente, filho do passado, está prenhe do futuro -, e dahi, erguendo temerário vôo, mostrar a filiação dos acontecimentos, e olhos fitos no que foi, vaticinar o que ha de ser; não, tão immodestas não são nossas pretenções, contentamo-nos com a ingloria fadiga de reunir, de modo que hum lanço d'olhos possão ser abrangidas, as occurrencias que mais influenciarão na sorte, quer da humanidade em geral, quer ainda na de qualquer das nações que, por mais avultarem no mundo ou por mais prezas comnosco se acharem pelos laços de reciprocos interesses, mais merecem nossa atenção. (JORNAL DO COMMERCIO, $1^{\circ}$ e 2 de janeiro de 1840: 1, grifos nossos) 
Ao enunciar seu papel, bem como o que dele se diferenciaria a historiografia, o jornal propõe que o jornalismo desempenha função registradora dos acontecimentos, estes, por sua vez, como dados que vão brotando da realidade.

Excusado nos he reproduzir aqui os acontecimentos a travez dos quaes foi esse acto consummado. As paginas do Jornal do Commercio ahi estão que pelo mundo, e debaixo das impressões do momento e da actualidade os narrão... (JORNAL DO COMMERCIO, $1^{\circ}$, 2/01/1841: 1, grifos nossos)

Nessas retrospectivas, o Jornal do Commercio dá a entender não somente ser capaz de dar conta da história mas também que lê-lo é suficiente para dela tomar parte. É interessante que, ladeados por representações do passado recente, apresentado como história, aparecem nessas passagens de ano anúncios das famosas Folhinhas Laemmert, calendário temático do ano seguinte. A presença desses elementos que evocam ideias de passado e futuro sugere que a manipulação diária de um periódico fornece mais do que informação, talvez a própria marcação cotidiana do tempo.

Os retrospectos anuais ganham destaque na década de 1840, sendo transformados em suplementos de duas páginas encartados nas edições regulares. Esse impulso registrador se exacerba na década de 1870, quando os suplementos passam a ser editados a cada dez dias, contendo as correspondências acumuladas nos dias anteriores. Na década seguinte, os suplementos desapareceram. Uma das hipóteses é que seu desaparecimento tenha se dado porque a lógica de aceleração foi incorporada à rotina produtiva jornalística graças à adoção do telégrafo em 1876.

Percebeu-se nessas retrospectivas um crescente esforço de atualização e conformação dos textos a partir da lógica da novidade, antes mesmo que novas tecnologias de comunicação, como o telégrafo, pudessem fornecer condições para a aceleração do ritmo dessa atualização. O jornal chegava mesmo a publicar boletins redundantes - "Tudo na mesma" (Supplemento ao n. 101, Jornal do Commercio, 03/04/1877) - e seus suplementos continham os "Telegramas de última hora" no pé da página 2, relatando as notícias "mais quentes" divulgadas pelos jornais europeus. Isso não era tudo. Depois dos "Telegramas de última hora", ainda vinha a coluna "Post escriptum".

Aí está a indicação do valor da novidade e da atualização produzida com a tecnologia possível da época. Ou seja, embora a tecnologia de emissão - a impressão - fornecesse o condicionante de um tempo diário, as narrativas condensavam outros tempos do fazer 
jornalístico naquele momento, o que incluía a espera dos paquetes. Além disso, a expectativa de atualização gradativamente se sobrepunha aos limites técnicos. O que se percebe aí é uma gradativa contração da extensão do tempo da notícia, remetendo a momentos cada vez mais rasos temporalmente.

Os suplementos eram dedicados a informações do exterior. Às vezes, o jornal elaborava um texto próprio, outras vezes dava a entender se tratar da transcrição literal das cartas, inclusive com local e data originais. Algumas dessas informações eram transcrições de periódicos europeus. No cabeçalho, lia-se como as notícias tinham chegado ao país: "Pelo paquete John Elder", "Pelo paquete Habsburg", "Pelo paquete Neva".

A notícia, portanto, não dependeria somente das tecnologias de transmissão, nem somente de técnicas redacionais, mas da relação permanente do leitor com as rotinas narrativas dos jornais, da sua inserção periódica no cotidiano, bem como das expectativas mais gerais da sociedade em relação ao jornalismo numa certa época. Assim, o mesmo status da notícia que foi sendo conformado pode em algum momento se diluir, dependendo da relação com o tempo que se experimenta.

Ainda que o hiato entre um acontecimento e sua configuração narrativa pela mídia fosse mais alargado do que hoje, parece fácil imaginar que o comerciante-leitor do Jornal do Commercio no século XIX não precisasse de lead e sublead, nem do boletim que anuncia que "Em 20 minutos, tudo pode mudar", para perceber as notícias fresquinhas. Até o pesquisador, inserido no seu próprio tempo, conforme estabelece contato periódico com os arquivos do jornal, torna-se capaz de perceber quais eram "as novas" naqueles imensos relatórios que a princípio parecem as edições do Jornal do Commercio de há 180 anos.

Não se pretende afirmar com isso que houvesse um embrião da notícia no século XIX, com estatuto e forma que adquiriria a partir da década de 1950 no Rio de Janeiro (RIBEIRO, 2000), mas que a percepção de ineditismo e do noticiário jornalístico não é estabelecida unicamente por uma deliberação profissional nem somente por fatores tecnológicos. Ela depende de todo o circuito de comunicação e do contexto nos quais as pessoas que fazem e que consomem um jornal estão inseridas, o que inclui o ritmo com que elas acionam esse circuito na sua vida prática.

\section{Cotidianidade}

À medida que o intervalo de projeção da notícia é encurtado, ampliando a expectativa de novas leituras atualizadas e consequentemente a necessidade do jornalismo, ao mesmo tempo, a intensidade da experiência cotidiana parece aumentar. 
Essa é a sensação que se tem frente à perecividade crescente do conteúdo das narrativas jornalísticas. Existe uma temporalidade que vai ganhando espaço e intensidade nos jornais que é o tempo do cotidiano. Embora o Jornal do Commercio publique o movimento dos portos e variações cambiais desde seu primeiro número, em 1827, afinal, esta era sua finalidade, esse tempo cotidiano vai sendo acentuado ao longo do século XIX e principalmente no XX. Esse movimento fica mais evidente em periódicos não especializados como o Jornal do Brasil e O Fluminense.

A partir de uma tipologia do uso do tempo por esses jornais, destacam-se: a) um tempo cosmológico (incluindo sua versão mística), usado para medir a passagem do tempo; b) um tempo historiográfico ou midiográfico, cujo uso é mais restrito, porém não menos importante para conferir um valor simbólico à prática jornalística; c) e finalmente um uso cotidiano, mais perecível, mas que talvez caracterize mais acentuadamente o jornalismo e que faz com que o classifiquemos como uma narrativa do presente.

Entre exemplos de uso cosmológico, há inúmeras referências à passagem do tempo, desde matérias, charges e artigos especiais de final de ano, a data diária no alto de página, previsão do tempo, efemérides em geral até o horóscopo. Também foram encontradas no Jornal do Brasil as "Notas Religiosas", em 1945, com hagiografias diárias do santo do dia, em diálogo direto com o calendário cristão. Em 1904, a obsessão com a precisão do tempo era tamanha que o jornal publicava uma lista de correspondência do dia aos calendários muçulmano, chinês, copta, positivista etc, além, é claro, dos nascimentos e ocasos do sol e da lua diariamente, o que fornece o sentido de passagem do tempo cósmico de modo mais óbvio.

O uso do tempo com pretensão historiográfica confere um valor simbólico especial aos jornais, como defensores da memória do país e registradores do tempo. Aos jornalistas, a semelhança com o trabalho do historiador também confere um poder especial, aproximandoos do ideal de um intelectual paradigmático, intérprete privilegiado do passado e, consequentemente, do presente.

Por exemplo, em 27 de abril de 1888, O Fluminense anunciou vender por 1\$000 o exemplar especial "O Abolicionismo Perante a História ou O Diálogo das Três Províncias" (O Fluminense, 27/04/1888: 4), que apresentaria uma síntese do problema. Durante o mês que antecedeu a abolição, o jornal publicou diariamente editoriais refletindo sobre as novas perspectivas econômicas. Ainda que O Fluminense se mostrasse favorável à abolição, fica patente a ansiedade que um grupo social por ele representado vivia quanto à futura organização da força produtiva. 
A necessidade de capitalizar simbolicamente aquele momento fica evidente na reprodução integral na primeira página do dia 16 de maio de 1888 da Lei Áurea. Os jornalistas acertaram na iniciativa, pois cem anos depois o jornal ainda explorava o fato de ter reproduzido a Lei, referendando a iniciativa em sua edição centenária (1978) e em outras seguintes (2008).

O Jornal do Brasil não havia completado um ano de circulação e já promovia sua coleção como registro relevante que deveria ser comprado e preservado. Embora não tenha produzido uma retrospectiva no seu primeiro ano, como fez o Jornal do Commercio, anunciou a venda de uma compilação de seus textos:

\section{Biblioteca do Jornal do Brasil}

Brevemente começaremos a editar em elegante volume in- 8 , nitidamente impresso em excellente papel e ao preço uniforme de $3 \$$ o volume ( $2 \$$ para nossos assinantes), o melhor de nossa collaboração estrangeira e nacional, sob o titulo geral de 'Biblioteca do Jornal do Brasil'

O primeiro volume está no prelo e terá por titulo Dom Pedro II e conterá todos os artigos publicados em nossa folha sobre o fallecido ex-Imperador. A este seguir-se-hão: Chronicas litterarias por Theophilo Braga, Dia a Dia, chronica alegre dos acontecimentos diários, Ephemerides brazileiras pelo Barão do Rio Branco, A Amazônia por José Veríssimo e successivamente os magnificos trabalhos expressamente para este jornal escriptos por Schimper. (JORNAL DO BRASIL, 30/12/1891: 1)

Desde seu primeiro ano, portanto, o Jornal do Brasil já atribuiu um valor de perenidade a seu trabalho, acrescentando valor simbólico extra a seu título. Fica evidente aí uma intenção registradora da passagem do tempo que se confundia com a ideia de história. A mesma percepção se repete em inúmeros exemplos nos três jornais estudados, o que leva a crer que esse era não só um modo próprio de pensar do século XIX, mas também uma concepção que oferecia "uma função" especial ao jornalismo e que talvez tenha se diluído ao longo do XX.

Mas a "função historiográfica" dos jornais continuaria por algum tempo. Em 1904, o Jornal do Brasil publicou sínteses semanais, os "Echos da Semana", aos domingos, da mesma forma que o Jornal do Commercio lançara seus suplementos quinzenais nos anos 1840-1870.

O mês de maio daquele ano de 1904 foi exemplar da função historiográfica que o Jornal do Brasil se atribuía. Fora mandado à Espanha um enviado especial para acompanhar o funeral da rainha Isabel II. Então o jornal explorou intensamente esse material. No dia 4/05/1904, p. 3, publicou página inteira com cinco ilustrações que dão bem a ideia do que se entendia por história. São ilustrações estáticas que não fornecem nenhum sentido de tempo, 
com exceção da dicotomia simples jovem/ velha. As legendas dizem: "Isabel II em 1860", "Isabel II em 1885", "retrato enviado por Isabel II á sua nora, a Rainha Maria Cristina", "Isabel II preparando-se para o acto de abidicação", "Isabel II em seus últimos dias". Com exceção da última, que apresenta uma velha de forma caricata aos olhos de 2010, as anteriores são totalmente redundantes. Parece que o esforço era apenas registrar e exibir capacidade gráfica, não importando se aquilo acrescentava algo ou não à compreensão do episódio. Tratava-se de outra sensibilidade para o tempo.

É importante ressaltar que a rainha da Espanha não era apenas “coisa do passado". Era também notícia fresca, a ponto de o jornal mandar um correspondente especial, mas o tratamento dado ao material era em parte "historiográfico", com análise do passado e das perspectivas para a Espanha com Afonso XIII, em parte descritivo da cerimônia fúnebre. Também é necessário lembrar que o Jornal do Brasil explorava fartamente a vida das famílias reais, as grandes celebridades da época, o que era fundamental para o periódico, talvez muito mais por ele ser popular do que por ser monarquista.

No 13 de maio, celebrou a "libertação da nossa Pátria do jugo da escravidão negreira" (O Fluminense, 13/05/1904: 1), analisando que a data "completou a obra do 7 de setembro." Assim, dizia que "as duas datas que se unificam, que se não podem separar, representam ambas acontecimentos que diretamente influíram para a construção do nosso organismo de nação livre e independente." Também comemorou o "96º aniversário da Imprensa”.

A respeito dessa creação, diz o padre Luiz Gonçalves dos Santos nas suas memórias do Brasil, p. 80: "O Brasil, até o feliz dia 13 de maio de 1808, não conhecia o que era typographia: foi necessário que a brilhante face do Príncipe regente nosso senhor, bem como o refulgente sol viesse vivificar este paiz, não só quanto á sua agricultura, commercio e industria, mas também quanto às suas artes e sciencias, dissipando as trevas da ignorância, cujas negras nuvens cobriam todo o Brasil e interceptavam as luzes da sabedoria. (JORNAL DO BRASIL, 13/05/1904: 1)

O mesmo trecho seria posteriormente reproduzido na edição centenária do Jornal do Commercio em 1927. Portanto, as efemérides, embora funcionassem como marcação de um tempo cíclico, eram também oportunidade de apresentar interpretações sobre o passado, usadas tanto isoladamente quanto vinculadas a análises mais amplas.

Durante suas primeiras décadas, o Jornal do Brasil publicou as "Ephemérides Brazileiras", escritas pelo Barão do Rio Branco, lembrando o que acontecera no Brasil a cada dia. A mesma lógica persiste nos jornais até hoje nas colunas ao estilo "Há 50 anos". Nesses exemplos, as efemérides são apresentadas de um modo muito autônomo, mas nem sempre foi 
assim, como, por exemplo, o editorial sobre a queda da Bastilha, na celebração do 14 de julho em O Fluminense, que o jornal aproveitou para realizar sua análise "historiográfica" da Revolução Francesa (14/06/1898).

Finalmente, o terceiro tipo de uso do tempo é a própria cotidianidade. A vida diária, na sua dimensão mais intensa, explode nas páginas de O Fluminense e no Jornal do Brasil desde o século XIX. Licitações de serviços públicos, assassinatos, navalhadas, notícias marítimas, suicídios, ataques piratas a cargueiros na costa, leilões, casamentos, aniversários, obituários, notas sociais, câmbio, classificados, "raptos e defloramentos", campanhas assistencialistas, medidas administrativas para garantir a qualidade da carne, ascensão do café na Europa são exemplos de conteúdo dos dois jornais entre as décadas de 1890 e 1920.

Fica patente aí a presença de algo que hoje poderia ser compreendido como noticiário. São preocupações as mais imediatas e pragmáticas possíveis: os classificados - alguém precisa vender alguma coisa e alguém precisa comprar, a escala dos comissários de polícia de plantão nas delegacias, o resultado do jogo do bicho - se alguém jogou, é preciso aplacar a expectativa mais imediata de saber se ganhou, a programação dos cinemas - também uma forma de planejamento do uso do tempo, entre tantos outros exemplos.

O anúncio da ampliação da Estrada de Ferro Central do Brasil, que ganharia uma quarta linha, pelo Jornal do Brasil, por exemplo, é, já em 1897, motivo de capitalização simbólica, como se o valor do "furo" e da exclusividade já estivesse presente ainda que derivado puramente de uma pragmática, o que é, afinal, o que importa quando se trata o jornalismo como prática social: "O público teve hontem conhecimento, por intermédio somente do Jornal do Brasil, de que esta importantíssima repartição vae ser dotada de um melhoramento de alta importância." (Jornal do Brasil, 04/04/1897: 1, grifo nosso)

Mas a cotidianidade não poderia ser descrita mais literalmente do que pela perecividade da carne na coluna do Jornal do Brasil "O BIFE", espécie de boletim de matadouros, onde se anunciavam diariamente as rezes abatidas, onde e por quanto comprar. Talvez a inscrição do jornalismo no cotidiano não possa ser mais claramente compreendida do que por esse exemplo. Imaginam-se tanto comerciantes procurando o melhor negócio quanto as famílias consultando os jornais para saber se poderiam consumir carne aquela semana e indo comprá-la rapidamente antes que o tempo a apodrecesse assim como à notícia.

\section{Considerações finais}

Concluiu-se até aqui que é preciso visualizar o jornalismo como atividade cujo valor não é tributável somente de significados recentes ou deliberações profissionais, sindicais, 
empresariais, acadêmicas, legais etc. É preciso buscar outros status que esse modo de interação social foi adquirindo ao longo do tempo para perceber os resquícios, as sobreposições, as transformações, as substituições, as radicais rupturas entre diferentes modos de fazê-lo e seus diferentes usos sociais.

A notícia, uma de suas principais marcas narrativas, aparece no passado como efeito da percepção de novidade dentro do fluxo comunicacional cotidiano, muito mais do que em decorrência de uma questão de forma - embora ela seja importante também. Como experiência particular do tempo, ela foi sendo reforçada e separada de análises "de fundo", que davam um panorama mais profundo temporalmente.

Assim, o leitor foi se satisfazendo com significados mais imediatos, enquanto o valor de perenidade do jornal foi sendo diluído. O passado foi se tornando mais raso, com pouca profundidade temporal (o que não significa que as pessoas tenham hoje menor capacidade de compreensão da sua historicidade).

A análise desses três periódicos sugeriu que a historiografia funcionava como signo ilustrativo, de exibicionismo de conhecimento que foi gradativamente perdendo o sentido de passado e projetando cada vez mais interesse para o futuro.

Também se chegou à conclusão que os significados do jornalismo mudam de acordo com o contexto, o grupo social, o período, o indivíduo. Seu sentido e os de suas mensagens são fruto de um trabalho permanente que se realiza sempre coletivamente na duração, enfim, processualmente.

Se o tempo que mais caracteriza o jornalismo é o presente, isso se dá não tanto pelo fato de os jornais falarem do presente, mas porque o presente é sentido por meio deles. Além disso, o jornalismo depende da percepção de novidade para garantir status comunicacional próprio e não ser compreendido como outras formas de representação, por exemplo, "literatura" (no sentido vulgar de obra de ficção), historiografia, fofoca, piada ou mito. Ele é uma captura particular do tempo e, nesse sentido, não faz muita diferença se aprisiona o passado ou o presente. Talvez o faça de ambas as formas.

\section{Referências bibliográficas}

BARBOSA, Marialva. "Reflexões sobre a imprensa no Brasil de 1808". In: Estudos em Jornalismo e Mídia, ano V, n. 2, pp. 91-109. julho/dezembro, 2008.

DARNTON, Robert. "Primeiros passos para uma história da leitura" In: $O$ beijo de Lamourette: Mídia, Cultura e Revolução. SP: Companhia das Letras, 2005, pp. 146-172. 
FRANCISCATO, Carlos Eduardo. A Fabricação do Presente. Como o jornalismo reformulou a experiência do tempo nas sociedades ocidentais. São Cristóvão: Editora UFS; Aracaju: Fundação Oviêdo Teixeira, 2005, 274 p.

JASMIN, Marcelo Gantus e FÉRES JUNIOR, João. "História dos conceitos: dois momentos de um encontro intelectual. In: JASMIN, Marcelo Gantus e FÉRES JUNIOR, João (orgs.). História dos conceitos: debates e perspectivas. RJ: Loyola, 2006.

MATHEUS, Leticia Cantarela. Comunicação, tempo, história. Tecendo o cotidiano em fios jornalísticos. Tese de Doutorado em Comunicação. Niterói (RJ): IACS-UFF, 2010.

MORAES E SILVA, Antônio. Diccionário da Língua Portuguesa. Lisboa: Typographia Lacérdina, 1813.

MOREL, Marco. As transformações dos espaços públicos: imprensa, atores políticos e sociabilidades na cidade imperial (1820-1840). SP: Hucitec, 2005.

MOTZKIN, Gabriel. "A intuição de Koselleck acerca do tempo na história.” In: JASMIN, Marcelo Gantus e FÉRES JUNIOR, João (orgs.). História dos conceitos: debates e perspectivas. RJ: Loyola, 2006.

RIBEIRO, Ana Paula Goulart. Imprensa e História no Rio de Janeiro dos Anos 50. Tese de Doutorado pela ECA/UFRJ, 2000.

RICOEUR, Paul. O si-mesmo como um outro. SP (Campinas): Papirus, 1991.

RICOEUR, Paul. Tempo e Narrativa. Tomo I. SP (Campinas): Papirus, 1994.

RICOEUR, Paul. Tempo e Narrativa. Tomo II. SP (Campinas): Papirus, 1995.

RIZZINI, Carlos. O livro, o jornal e a tipografia no Brasil (1500-1822). Com um breve estudo geral sobre informação. RJ, SP, RS: Livraria Kosmos Editora, 1946.

\section{Material analisado}

Jornal do Commercio: edições de maio, junho e setembro de 1908, outubro de 1928; novembro e dezembro de 1827 , janeiro de 1930 , janeiro de 1836 , dezembro de 1837 , janeiro de 1840 , janeiro de 1841 , janeiro de 1842 , janeiro de 1847 , fevereiro de 1857 , fevereiro de 1858 , março de 1867 , abril de 1877 , maio de 1887 , junho de 1897 , dezembro de 1899 , julho de 1907 , agosto de 1917 , setembro de 1927 , outubro de 1937 , novembro de 1947 , janeiro de 1948.

O Fluminense: edições de maio de 1888, abril de 1897, julho de 1898, setembro de 1915 , novembro de 1936, fevereiro de 1942; abril de 1971.

Jornal do Brasil: edições de dezembro de 1891, setembro de 1945, novembro de 1967, dezembro de 1983. 